Lexis XXIV. 1 (2000): 187-194.

\title{
Alberto Escobar Sambrano (1929-2000)
}

El 30 de mayo del presente año dejó de existir en la ciudad de Framingham, Massachussetts (Estados Unidos) don Alberto Escobar Sambrano, ilustre lingüista, miembro de número de la Academia Peruana de la Lengua. Nacido en Lima el 23 de octubre de 1929, el llorado maestro, colega y amigo, fue hijo de don Manuel Escobar Monterrey y de doña Mercedes Sambrano. Cursó estudios secundarios en el Colegio Italiano "Antonio Raimondi" (1941-1945), y universitarios en la cuatricentenaria Universidad Nacional Mayor de San Marcos (1946-1951). Prosiguió sus estudios, esta vez de especialización, en las Universidades de Florencia (1952-1953), la Central de Madrid (1954-1955), y, finalmente, en la de Munich (19551958). Los grados obtenidos tras su formación académico-profesional fueron los de Bachiller en Humanidades, por la Universidad de San Marcos (1952), Doctor en Letras, por la misma Universidad (1958), y Doktor der Philosophie, por la Universidad de Munich (1960). De su matrimonio con la Sra. Bertha Basurto Bernard deja cuatro hijas: Anna María, Susanne, Silvana y Bettina, de las cuales la primera sigue los pasos de lingüista de su ilustre progenitor.

En 1989, conmemorando su sexagésimo aniversario, sus discípulos y amigos Enrique Ballón Aguirre y quien escribe, le tributamos un volumen de homenaje que llevaba por título en verdad emblemático Diglosia linguo-literaria y educación en el Perú (Lima: CONCYTEC y GTZ, 1990). El libro colectivo buscaba ofrecer entonces una temática varia que cubriera los diversos campos a los cuales don Alberto Escobar les había dedicado especial atención a lo largo de su fructífera carrera académica e investigatoria de lingüista y crítico literario. El "Memento bio-bibliográfico" que precede el volumen mencionado (pp. 15-32) constituye, por lo menos hasta 1990, el más 
completo testimonio de su intensa actividad docente y profesional, reflejada en la nutrida bibliografía que se ofrece, a la par que en las justas y merecidas distinciones de que fuera objeto hasta entonces.

En apretada síntesis, y sin tomar en cuenta su obra poética de juventud, de la cual nos confesaba alguna vez haber abjurado (para quedarse sólo con algunos poemas que, reproducidos bellamente, adornaban las paredes de su sala), las distintas áreas en las cuales don Alberto Escobar desplegó su admirable capacidad analítica y reflexiva, tanto en la cátedra sanmarquina como en los centros de investigación que paralelamente fundó y dirigió, pueden resumirse en los siguientes rubros: crítica literaria y filológica, análisis linguístico-descriptivo, dialectología y sociolingüística, y política lingüistica y educativa.

Como lingüista y discípulo, más bien profano en materia de crítica literaria, campo en el cual el recordado maestro hizo grandes aportes incorporando primeramente el análisis estilístico y posteriormente el semiótico, aplicados al estudio y comprensión de nuestros clásicos de la literatura peruana (Salaverry, Palma, Garcilaso, Alegria, Vallejo, Arguedas, entre otros), y demostrando, al paso, la necesidad del enfoque lingüistico en el ejercicio de la exégesis literaria, nos limitaremos a ofrecer aquí un justo y merecido recuento de algunos de los aportes más saltantes de su legado lingüístico siempre comprometido con una realidad compleja e incomprendida como la peruana, secularmente plurilingüe y multicultural.

En el terreno de la lingüística propiamente dicha, don Alberto Escobar desempeñó un rol decisivo en la reorientación de los estudios del antiguo Instituto de Filología de la Universidad de San Marcos, cuya preocupación giraba más bien en torno a las lenguas clásicas, promoviendo la creación de su Departamento de Linguística, que volcará su atención a la realidad nacional, un tanto soslayada hasta entonces, constituyéndose pronto en un verdadero semillero del cual egresará más tarde la primera promoción de especialistas en la disciplina, algunos de los cuales se abocarán al estudio de nuestras lenguas indígenas. En tal sentido, Alberto Escobar no solamente es el introductor de la lingüística descriptiva en el Perú a través de las cátedras que desempeñó, y cuyo énfasis en el trabajo de campo pronto daría sus frutos, sino que él mismo llevó a la práctica dicha preocupación, como lo prueban sus trabajos sobre algunas variedades que- 
chuas (de Pasco y Chachapoyas, concretamente). Y, más allá de la cátedra, la misma preocupación en favor de una linguística peruana lo llevó a crear el Plan de Fomento Lingüístico de la misma Universidad (del que fue su Director entre 1964 y 1967), y más tarde, en 1969, juntamente con un grupo de reconocidos científicos sociales, fundará el Instituto de Estudios Peruanos, encargándose de la línea de investigación lingüistica de dicho centro. Gracias al impulso que supo darle a esta actividad de fomento y desarrollo, la lingüística peruana adquirió mayoría de edad, siendo reconocida como tal en los foros internacionales del ámbito latinoamericano patrocinados, entre otros, por el Programa Interamericano de Lingüística y Enseñanza de Idiomas (PILEI), del cual fuera miembro fundador, y por la Asociación de Linguiística y Filología de la América Latina (ALFAL).

En el campo más específico del estudio de las lenguas andinas y del castellano peruano, Alberto Escobar tendrá un rol verdaderamente protagónico, gracias al trabajo de barbecho y cultivo previamente desarrollado en su alma mater. Así, cuando el gobierno militar del general Velasco Alvarado oficializa el quechua por DecretoLey 21156 del 27 de mayo de 1975, le tocó al recordado maestro e investigador, que hasta entonces había sido convocado por las autoridades del gobierno en calidad de asesor y consultor en materia linguística y educativa, integrar la Comisión de Alto Nivel encargada de formular recomendaciones para la implementación de dicha medida oficial, en cuyo seno tuvimos la oportunidad de trabajar. Una de las acciones inmediatas que se tomaron entonces fue la codificación de seis variadedes quechuas que fueron seleccionadas del conjunto de lenguas y dialectos que integran la familia lingüística, la misma que en el predio de los no iniciados parecía identificarse sólo con el dialecto cuzqueño, lingüísticamente menos conservado que el resto de sus congéneres, aunque rodeado de indudable prestigio histórico. Dicha tarea supuso, en primer lugar, la propuesta de un alfabeto general pandialectal unificado que, algunos años después, con ligeras modificaciones, se constituirá en el alfabeto oficial vigente (desde 1987); y, en segundo lugar, la elaboración y publicación de seis gramáticas quechuas con sus respectivos vocabularios, correspondientes a las variedades seleccionadas (San Martín, CajamarcaCañaris, Ancash-Huailas, Junín-Huanca, Ayacucho-Chanca y Cuzco- 
Collao), editados en 1976 conjuntamente por el Ministerio de Educación y el Instituto de Estudios Peruanos. La labor de coordinación de todo este esfuerzo en el que participamos tanto quechuistas nacionales como extranjeros, y cuya virtud está en haber dado a conocer por primera vez en la historia del quechua, algunas de sus variedades hasta entonces olvidadas, estuvo a cargo precisamente de quien había sentado las bases de los estudios de lingüística amerindia en el país.

La preocupación de don Alberto Escobar por las lenguas indígenas no excluyó por cierto su interés por el estudio del castellano peruano, en deuda con su orientación en lingüística románica adquirida en Europa, y esta vez contando con la ventaja de una formación tributaria de dos importantes tradiciones: filológica-europea la una y descriptivo-norteamericana la otra. Así, pues, buena parte de sus reflexiones linguísticas las consagró al estudio del castellano peruano, que hasta entonces había quedado trunco, luego del trabajo juvenil de don Pedro Benvenutto Murrieta. Su primer ensayo sobre el tema, "Tipología, variedades y zonificación del español del Perú: propuesta para un debate", que fue leido en el acto de su incorporación como miembro de número de la Academia Peruana de la Lengua (1976), constituye el principio de una serie de trabajos que formarán parte integrada de su libro Variaciones sociolingüísticas del castellano en el Perú (Lima: IEP, 1978). El título de la obra, como se ve, ya anuncia un enfoque novedoso: el sociolinguístico, que supera y liquida la práctica de la vieja dialectología que hasta entonces no solamente se apoyaba casi de manera exclusiva, en cuanto al material estudiado, en datos provenientes de la literatura costumbrista, sino que no pasaba de la consideración de la variación diatópica, es decir que operaba al margen del entorno societal, respondiendo a prácticas e ideologías de corte normativista en una sociedad tan marcada por la diversidad idiomática y las barreras económicas y socioculturales que hacen del país una realidad fracturada. Aun cuando podrá discreparse de la tipología del castellano andino propuesta por el autor, habrá que reconocer que el suyo es el primer esfuerzo por ordenar y clasificar, sobre la base de datos empíricos recogidos en el campo, la compleja realidad dialectal del castellano peruano, a la que no le es ajena, desde los tiempos del Inca Garcilaso y de Guaman Poma, la modalidad del castellano andino, incor- 
porada por Escobar de manera orgánica dentro de los estudios hispanísticos.

De otro lado, como se sabe, precisamente en un intento por cancelar los mecanismos de opresión idiomática vigentes en el país, según voceros del gobierno militar, se declaraba el quechua como lengua oficial en el entendido de que esta medida formaría parte integral del conjunto de reformas estructurales efectuadas en el plano cultural, dentro de un proyecto que buscaba rediseñar una nueva sociedad que empezara por reconocer, esta vez, su verdadero rostro de país multiglósico y pluricultural. El debate nacional suscitado por una medida tan audaz como la mencionada obligaba a una gran reflexión sobre el tema y sus implicancias dentro de una política global de estado. Había llegado el momento en que los lingüistas, hasta entonces indiferentes a toda convocatoria que los distrajera de sus afanes estrictamente glotológicos, terciaran activamente en dicho debate. Urgía la participación del especialista para ofrecer un diagnóstico de la realidad nacional que permitiera formular políticas idiomáticas congruentes con el programa de gobierno propuesto. El diagnóstico nos lo ofrecerá Alberto Escobar en el trabajo, ya clásico, El reto del multilingüismo en el Perú (Lima: IEP, 1972), esfuerzo colectivo en el que se recoge una serie de ensayos que inciden precisamente en la realidad linguiistica peruana, pasada y presente, signada por la incomunicación secular instaurada por la colonia y heredada por los fundadores de nuestra república, pero cuyo reconocimiento debe ser el punto de partida de toda política idiomática justa y equitativa. Precisamente la imagen de esa sociedad acariciada, donde la heterogeneidad no es vista como estorbo sino como riqueza ancestral, se proyecta en el ensayo Perú, ¿país bilingüe? (Lima: IEP, 1975), cuyo aporte lingüístico es de la autoría de nuestro colega académico, y cuyo título, con pregunta más bien retórica, sigue recordándosnos el anhelo de la sociedad peruana, de ascendrada milenaria vocación plurilingüe. En retrospectiva, contrariamente a lo que podría pensarse, más aún pasados algunos lustros luego de su aparición, sería un error ver en dicho libro una obra meramente coyuntural y anacrónica: por el contrario, y en la medida en que persisten los problemas de injusticia social y linguística, sigue siendo una suerte de denuncia a la par que una guía que nos recuerda la deuda glotopolítica pendiente de solución. 
En el terreno de la política educativa, estrechamente vinculado al idiomático, don Alberto Escobar tuvo igualmente una participación muy activa, como maestro, lingüista e investigador. Ya desde su intervención en la memorable "Mesa redonda sobre el monolingüismo quechua y aimara y la educación en el Perú", organizada por la Casa de la Cultura, entonces bajo la dirección del célebre novelista José María Arguedas (1963), vemos al joven sanmarquino abogar enfáticamente por una educación bilingüe en favor de los grupos monolinguies quechuas y aimaras, cuya población escolar continuaba siendo objeto, como hasta ahora todavía, de una enseñanza directa y tradicional del castellano como si esta lengua fuera la materna de aquélla. En aquel debate Escobar se encargará de hacer importantes deslindes conceptuales como, por ejemplo, la diferencia que existe entre alfabetizar y castellanizar, nociones a menudo peligrosamente confundidas incluso en la actualidad entre quienes tienen en sus manos las campañas de alfabetización; de igual modo, había que distinguir entre enseñanza de lengua materna y enseñanza de segunda lengua, nociones igualmente mal asimiladas y peor comprendidas en nuestro medio. Comprometido con una educación bilingüe como alternativa destinada a resolver o al menos aliviar el drama escolar de la población monolinguie, don Alberto Escobar organizará un programa experimental bilingüe quechua-castellano en la región de Quinua (Ayacucho) como una de las acciones desarrolladas por el Plan de Fomento Lingüístico. De esta manera el centro aludido, dirigido por el recordado maestro, no sólo alentará la investigación puramente lingüística sino también la aplicada. De hecho, además del Proyecto de Quinua, el PFL ensayará en la Universidad de San Marcos, por primera y única vez en su historia, la enseñanza de idiomas modernos, incluyendo el quechua, con el entonces novisimo método audiovisual que tenía la virtud de garantizar un verdadero aprendizaje de la lengua meta: sólo de esta manera descubrimos los escépticos que también se podía aprender el quechua más allá de la mera repetición de frases hechas o de palabras descontextualizadas. Más tarde, la experiencia del proyecto de Quinua se multiplicará, y, acorde con los planteamientos del indigenismo moderno, se reclamará no ya una educación bilingüe de corte transicional (connatural a una ideología asimilacionista o integracionista), que era la abogada por entonces, sino otra, de mantenimiento y desarrollo, que propen- 
da a una práctica plurilingüe e intercultural, única vía para alcanzar el verdadero desarrollo social y económico del país así como para buscar resolver sus problemas de identidad. Don Alberto, como lo llamábamos familiarmente, no fue ajeno a estos cambios: de allí que continuó apoyando todos los esfuerzos destinados a romper con el método tradicional de enseñanza directa del castellano propugnado por las autoridades educativas gubernamentales. Concretamente, dos fueron en este último campo los temas que le preocuparon: la norma castellana que debía impartirse en los centros de enseñanza, especialmente andinos, y la concientización del maestro de la necesidad de los principios básicos de la linguística como herramienta para un desempeño más eficiente. Escribió al respecto varios ensayos, algunos de los cuales aparecen en el volumen que lleva por título Lenguaje y discriminación social en América Latina (Lima: Milla Batres Editor, 1972). Si el segundo cometido sigue en pie, por el carácter obvio de sus implicancias pedagógicas, el primero, cuya propuesta se inclinaba por la selección de diversas normas (locales, regionales y finalmente general), aguarda todavia, y al margen de sus bondades como alternativa de selección, un mejor conocimiento de las distintas modalidades que ofrece el castellano en el país.

Aquejado de un mal cardíaco congénito, don Alberto supo sobrellevar una vida llena de sobresaltos pero atemperada por el trabajo siempre creativo y esclarecedor. El destino le depararía todavía una prueba más dolorosa en 1980 , cuando se encontraba como profesor visitante en la Universidad de Grenoble III, al sufrir la picadura de una abeja africana que lo puso al borde de la muerte. Su recuperación, verdaderamente milagrosa, fue lenta y penosa, habiendo logrado superar parcialmente el don de su palabra amenazada por el silencio. En tales horas difíciles, como diría él mismo, su esposa Betty le "prestaría su voz". Pasados los trances más angustiosos, don Alberto retomó sus actividades investigatorias en el IEP, esta vez retirado de la vida pública. Fue entonces cuando dio a la imprenta el trabajo iniciado en Grenoble: Arguedas o la utopia de la lengua (Lima: IEP, 1984).

Alejado del Perú desde 1990 se radicó en los Estados Unidos, primero en la ciudad de Columbia de Missouri y posteriormente en la de Framingham, Massachussetts. Desde allí, sin perder el contacto con sus amigos y discípulos, prosiguió con su tarea intelectual, 
dando a conocer trabajos inéditos y revisando y ordenando otros tantos estudios publicados con anterioridad, sobre todo aquellos que habían sido relegados en favor de sus afanes estrictamente linguísticos: los de crítica literaria. Testimonio de esto último es su Patio de Letras 3 (Lima: Luis Alfredo Ediciones, 1995), cuyo lanzamiento contó con la presencia del ilustre autor.

La muerte implacable sorprende a este infatigable estudioso de nuestra realidad privando a sus colegas y discípulos de la amistad sincera, del consejo oportuno y de la voz rectora que siempre supo prodigarnos generosamente. Quienes intentamos seguir su ejemplo no tenemos otro tributo que ofrecerle sino el trabajo propio inspirado en el ejemplo y en las enseñanzas del llorado maestro.

Rodolfo Cerrón-Palomino 